\title{
El consumo cultural en América Latina Guillermo Sunkel, coordinador Convenio Andrés Bello, 2006 (Segunda edición ampliada y revisada) 535 páginas
}

\section{Loreto REBOLLEDO}

En 1999 apareció la primera edición de El consumo cultural en América Latina, que a partir de un conjunto de artículos provenientes de diferentes autores y disciplinas buscaba dar cuenta de las principales tendencias teóricas y líneas de investigación desplegadas en la región sobre los procesos de comunicación y transformaciones culturales. Un aspecto novedoso del libro era el acento en las audiencias y sus modos de interpelar, releer, disolver o resistir los mensajes emitidos por los diferentes medios.

El libro, coordinado por Guillermo Sunkel, fue celebrado por estudiosos de la comunicación e investigadores interesados en los estudios culturales que encontraron allí una interesante selección de investigaciones realizadas en diferentes países del continente a los cuales era difícil acceder dada su dispersión. Esto convirtió al libro en un referente obligado de los estudiantes de comunicación que accedieron así a artículos de conocidos autores como Jesús Martín-Barbero, Guillermo Orozco, Néstor García Canclini, María Cristina Mata, entre otros.

Siete años después aparece esta segunda edición de "El consumo cultural en América Latina”. Se trata de una versión revisada y ampliada, que conserva el núcleo central de la compilación anterior y su misma organización en cuatro partes: Aproximaciones teórico metodológicas, usos y prácticas de consumo cultural, apropiación del arte y el patrimonio y consumo de medios; a la cual se han agregado siete nuevos artículos que dan cuenta de nuevos procesos comunicacionales y de consumo cultural que han irrumpido en América Latina en estos años.

La "puesta al día" implicó también la revisión de los artículos por parte de sus autores. El capítulo sobre el consumo de medios, que presenta las mayores modificaciones, fue enriquecido con artículos referidos al cine e Internet, los cuales se agregaron a prensa, radio y televisión. Además se incluyó a los niños como receptores de la televisión.

Un aspecto destacable de esta compilación es que da cuenta de la heterogeneidad de aproximaciones al tema del consumo cultural, tanto en lo referido a lo teórico como al modo de abordar metodológicamente las investigaciones; lo que hace manifiesto el que pese a los avances hay un desafío abierto. Como señala Guillermo Sunkel "Desafío teórico porque no existe un modelo capaz de describir y explicar los procesos de conusmo cultural, los que son regulados por muy diversas racionalidades: económicas, políticas y simbólicas. Desafío metodológico pues no existe una modalidad privilegiada para abordarlo en la investigación empírica”.

Guillermo Sunkel es sociólogo, PhD en Estudios Culturales de la Universidad de Birmingham, fundador y ex director del Centro de Estudios de la Comunicación del Instituto de Comunicación e Imagen de la Universidad de Chile 